\title{
A AVALIAÇÃo DA PÓS-GRADUAÇÃO NO BRASIL
}

\author{
Alguns Pontos Para sua COMPREensão e Discussão
}

\author{
MAURicio DE AlmeidA ABREU
}

R E S U M O No Brasil, os programas de pós-graduação strictu sensu são avaliados anualmente pela Capes. Trata-se de processo complexo, necessário e importante, que vem sendo aprimorado a cada ano. A atividade de avaliação possui a grande vantagem de ser realizada pela própria comunidade acadêmica, figurada na Capes por representantes de área, comissões de área e representantes de grande área. Atenção especial é dada pelas diferentes comissōes à avaliação qualitativa e quantitativa da produção científica. O sistema tem sido falho, entretanto, ao não associar claramente a atividade de avaliação com a politica de fomento acadêmico, disso resultando incongruências graves que precisam ser rapidamente sanadas. Este texto objetiva esclarecer a estrutura do processo de avaliação da Capes, indicando, ponto a ponto, como ele funciona.

P A L A V R A S - C H A V E Capes; programas de pós-graduação; avaliação.

Para a discussão do processo de avaliação continuada dos programas de pós-graduação, realizado anualmente pela Capes, os seguintes pontos - entre muitos outros - merecem ser considerados pela Anpur.

\section{A IMPORTÂNCIA DO PROCESSO DE AVALIAÇÃO}

No Brasil, os programas de pós-graduação strictu sensu são avaliados anualmente pela Capes. Trata-se de processo complexo, necessário e importante. Obviamente, não é perfeito, mas vem sendo aprimorado a cada ano. Embora esteja sujeita a críticas, muitas delas justificadas, a atividade de avaliação possui a grande vantagem de ser realizada pela própria comunidade da pós-graduação, composta na Capes por representantes de área, comissões de área e representantes de grande área. São, portanto, os pares que têm a responsabilidade de avaliar a pós-graduação. Apoiar e garantir a continuidade e aprimoramento desse processo - um dos melhores do mundo - deve ser um objetivo de todas as associaçōes científicas.

\section{REPRESENTANTES DE ÁREA, COMISSÕES DE ÁREA E REPRESENTANTES DE GRANDE ÁREA}

Cada área do conhecimento possui um(a) representante na Capes, escolhido(a) por consulta feita aos programas de pós-graduação. Essa pessoa é a interlocutora da área e tem 
um mandato de três anos. Cabe à representação de área compor uma comissão de área, que atue no sentido de prestar-lhe assessoria direta, participando, por exemplo, da avaliação anual dos programas de pós-graduação e do julgamento dos pedidos de implantação de cursos novos. A designação dos integrantes das comissões de área é responsabilidade única e exclusiva do(a) representante de área, que pode fazê-lo com ou sem consulta a associaçōes científicas. As comissões podem ser permanentes ou temporárias, mas é comum que sejam compostas obedecendo critérios de participação interna das subáreas de conhecimento que compõem a área e de representatividade regional.

Há 46 áreas do conhecimento (e, portanto, 46 comissões de área), que são, por sua vez, agregadas em 11 grandes áreas: Ciências da Saúde, Ciências Biológicas, Ciências Exatas, Engenharias, Ciências Humanas, Ciências Sociais Aplicadas, Ciências Agrárias, Letras e Linguística, Artes, Ensino de Ciências e Multidisciplinar. Todas as grandes áreas têm representação no Conselho Técnico Científico (CTC), que é a instância homologadora de decisões relativas à avaliação da pós-graduação no País. Com exceção das quatro últimas grandes áreas, que possuem apenas um representante no СTC, as demais possuem dois. Todos os representantes de grande área são eleitos por consulta feita aos representantes das áreas que a compõem. $\mathrm{Na}$ Capes, as áreas mais representativas da Anpur fazem parte de duas grandes áreas do conhecimento: Ciências Sociais Aplicadas (que congrega Planejamento Urbano e Regional, Arquitetura e Urbanismo, Comunicação, Direito, Economia, Demografia, Serviço Social e Administração/Turismo) e Ciências Humanas (que inclui Geografia, História, Sociologia, Ciência Política, Antropologia, Educação, Psicologia e Filosofia/Teologia).

\section{OS RELATÓRIOS ANUAIS DOS CURSOS E SUA UTILIZAÇÃO PELAS COMISSÕES}

O processo de avaliação tem início com o envio anual, pelos diversos programas de pós-graduação, de um relatório que dá conta das atividades desenvolvidas nos últimos doze meses (docentes envolvidos, número de teses e dissertações defendidas, produção científica docente e discente, disciplinas ministradas etc.). Com base nessas informaçōes brutas, a Capes prepara uma série de tabelas e índices que são depois disponibilizados às comissões de área. Embora as fichas de avaliação sejam idênticas para todas as áreas (incluindo quesitos relativos à Proposta do Programa, Corpo Docente, Atividades de Pesquisa, Atividades de Formação, Corpo Discente, Teses e Dissertações e Produção Intelectual), cada comissão é livre para estabelecer os pesos que considera adequados para cada um deles, respeitados certos limites máximos e mínimos estabelecidos pela Capes. Da mesma forma, cada comissão é livre para estabelecer métodos próprios de análise das informações fornecidas pelos programas, algumas optando por pautar seu julgamento quase que exclusivamente por critérios quantitativos, outras optando por um maior equilíbrio entre critérios quantitativos e qualitativos. Para assegurar a transparência do processo de avaliação, a Capes disponibiliza, em sua página na Internet (www.capes.br), um documento preparado por cada uma das comissões de área (chamado Documento de Área), que explicita os critérios de avaliação por elas utilizados. 


\section{AVALIAÇÃO CONTINUADA}

Atualmente, o processo de avaliação dos programas de pós-graduação é conhecido como "avaliação continuada". O qualificativo indica que se trata de um processo ininterrupto de análise da pós-graduação, que permite que cada comissão de área acompanhe de perto o desempenho dos programas que lhe são vinculados. A cada três anos de avaliação continuada as comissōes atribuem aos cursos um conceito que varia de 1 (mínimo) a 7 (máximo). Para serem oficializados pelo Conselho Nacional de Educação, os conceitos atribuídos pelas comissóes precisam ser homologados pelo Conselho Técnico Científico (СТC) da Capes, que tem poder para manter ou alterar as decisōes das comissóes.

Até 1996, a avaliação dos cursos de pós-graduação utilizava letras, em vez de números, e era interna a cada área. Em outras palavras, o melhor curso de uma área obtinha, invariavelmente, o conceito A, seguindo-se-lhe outros classificados como B, C etc. A partir de 1997, entretanto, o sistema de avaliação mudou. Na tentativa de estabelecer critérios que permitam a comparação entre as diversas áreas, a Capes vem adotando uma hierarquização de notas que só é ordinal até certo nível da escala de classificação, fato que tem originado tensões interáreas. Segundo o sistema em vigor, cursos com nota 1 e 2 não são reconhecidos pela Capes; por essa razão, eventuais diplomas por eles emitidos não têm reconhecimento oficial do Ministério da Educação. As notas 3, 4 e 5 garantem o reconhecimento oficial da Capes e sinalizam, grosso modo, um nível de qualidade regular, bom e muito bom, respectivamente. Notas 6 e 7 são indicadoras de excelência e premiam cursos que, além de se destacarem no cenário nacional como centros de referência, possuem também inserção internacional. É sobretudo em relação a esses dois últimos níveis que surgem as tensões, conforme será discutido mais adiante.

\section{A IMPORTÂNCIA DA PRODUÇÃO CIENTÍFICA}

A grande maioria das comissōes de área confere peso elevado à produção intelectual docente. A sua mensuração, entretanto, varia conforme a especificidade de cada área. Há áreas que privilegiam a publicação apenas em periódicos internacionais, que são hierarquizados em função de índices de impacto ou de citação fornecidos por instituições privadas que monitoram o que é publicado (e citado) nas revistas científicas; é o caso, por exemplo, das áreas que integram as Ciências Biológicas e as Ciências da Saúde. Nas Engenharias, as conferências em congressos possuem o maior peso. Já para as Ciências Exatas, é muito importante a publicação em anais de congressos. As Artes, por sua vez, precisam ter critérios bastante específicos de mensuração da produção (no caso, artística). As Ciências Humanas e as Ciências Sociais Aplicadas dão destaque a quatro tipos de produção: livros, capítulos de livros, artigos em periódicos e trabalhos completos em anais.

\section{QUALIS}

Visando garantir maior homogeneidade ao julgamento da produção intelectual pelas diversas áreas, sobretudo no que diz respeito à produção bibliográfica, a Capes vem solicitando às comissões que estabeleçam uma hierarquização dos veículos de publicação utilizados por seus profissionais segundo critérios de circulação (internacional, nacional e 
local) e de qualidade (A, B e C). A essa classificação dá-se o nome de Qualis. Seu objetivo é não apenas fornecer uma avaliação, anualmente renovada, dos veículos utilizados por cada área, mas oferecer também uma sinalização que oriente cada pesquisador em sua decisão sobre o melhor destino a dar à sua produção científica. No momento atual, quase todas as áreas de avaliação da Capes já contam com o Qualis. Nas humanidades, os Qualis são mais recentes e muitos apresentam-se ainda provisórios e incompletos. Embora sua aplicação no processo de julgamento tenha estimulado uma série de críticas por parte de diversas comunidades científicas, que o consideram uma interferência desnecessária e indevida da Capes sobre a vida acadêmica, a verdade é que os Qualis, refinados a cada ano pelas diversas comissões, vêm tendo um papel decisivo na elevação da qualidade técnica e científica dos veículos de divulgação da produção das ciências humanas e sociais.

\section{ÁREAS E GRANDES ÁREAS: NECESSIDADE DE INTEGRAÇÃO}

Como já discutido, o processo de avaliação continuada permite que cada área do conhecimento estabeleça, de forma autônoma, seus próprios critérios e parâmetros de julgamento. Todavia, como as avaliações finais de cada área precisam ser homologadas pelo CTC, que se estrutura em nível de grande área, cada vez mais faz-se necessário estabelecer normas e procedimentos comuns de grande área, que possibilitem maior integração entre as diversas áreas que a compõem, sobretudo no que toca a definição de critérios de excelência.

A última avaliação trienal foi traumática para a maioria das áreas das humanidades, que viram os conceitos conferidos por suas comissões ser alterados para baixo pelo CTC. Dessa experiência resultou, entretanto, o reconhecimento de que, em comparação às chamadas "ciências duras", que atuavam relativamente em bloco no CTC, exibindo grande homogeneidade de critérios, as ciências humanas e sociais caracterizavam-se pela multiplicidade de critérios e pela falta de integração, situação que era responsável, em grande parte, por sua fragilidade. Tentando reverter essa situação, faz-se agora um esforço concentrado para aumentar a integração, não apenas entre as áreas que compõem as Ciências Humanas e Ciências Sociais Aplicadas, mas também entre essas duas grandes áreas. A aproximação vem sendo buscada também com as grandes áreas de Letras e Linguística, Artes e Ciências Agrárias, com as quais possuímos interfaces importantes.

\section{A AVALIAÇÃO 2004 JÁ COMEÇOU}

Ao mesmo tempo em que as áreas que compõem uma grande área fazem esforços para aumentar sua integração, é fundamental que se estabeleça, ainda em 2003 e conjuntamente (isto é, Ciências Humanas + Ciências Sociais Aplicadas), os fundamentos que nortearão a atuação das comissões na avaliação de 2004. Para que não haja problemas com a homologação posterior no CTC, é também necessário que as grandes áreas consigam aprová-los previamente no CTC, evitando-se, com isso, as tensões que pautaram a homologação de 2001. Nesse sentido, as grandes áreas de Ciências Humanas e de Ciências Sociais Aplicadas vêm correndo contra o tempo para tentar estabelecer definições, critérios e parâmetros de julgamento que sejam comuns às áreas que as compóem. Como os 
maiores pontos de tensão dizem respeito à atribuição das notas 6 e 7, é fundamental definir também o que se entende por "inserção internacional" nessas grandes áreas e indicar os parâmetros que podem ser usados para mensurá-la. Com o intuito de exemplificar o que vem sendo discutido, apresentamos, em anexo, os critérios de excelência aprovados pela Grande Área de Ciências Humanas em reunião de 26/6/2002 e já apresentados ao CTC. São critérios que ainda merecem mais detalhamento, tarefa que será realizada em conjunto com a Grande Área de Ciências Sociais Aplicadas.

\section{AVALIAÇÃO E FOMENTO: DUAS FACES DA MESMA MOEDA QUE NEM SEMPRE SE COMPLETAM}

$\mathrm{Na}$ Capes, as atividades de avaliação e de fomento, pilares básicos do sistema de acompanhamento da pós-graduação, nem sempre se equilibram. Às comissões de área cabe, sobretudo, a tarefa de avaliar. Embora a atividade de avaliação acabe produzindo efeitos no fomento, em especial no que toca as quotas de bolsas e de recursos financeiros dos programas, a verdade é que o fomento tem também um movimento próprio, independente das atividades das comissões, o que, não raro, produz situações paradoxais e contraditórias.

\section{AS ASSOCIAÇÕES CIENTÍfICAS E A CAPES}

Os representantes de área e de grande área vêm sendo constantemente lembrados pela Capes de que as diversas áreas do conhecimento (e suas respectivas sociedades científicas) podem e devem ter um papel mais decisivo no fomento. Segundo essa cobrança, as sociedades científicas deveriam influir mais no estabelecimento da política de pós-graduação, fornecendo à Capes propostas efetivas de atuação nas áreas que representam. Isso incluiria, por exemplo, a definição pelas sociedades científicas, a cada triênio, dos programas de fomento que deveriam ser priorizados na sua área de atuação: por exemplo, que modalidade de bolsas desejam ver incentivadas (mestrado e doutorado no País?, pós-doutorado no exterior?). Poderiam também recomendar a adoção de programas de ação induzida, visando à melhor capacitação de uma determinada área ou subárea do conhecimento. A Anpur pode e deve fazer uso desse canal de pressão.
Maurício de Almeida Abreu, geógrafo, é professor da Universidade Federal do Rio de Janeiro e representante da área de Geografia na Capes.

E-mail: abreu@igeo.ufrj.br

Artigo recebido para publicação em novembro de 2002 
A A V A L I A Ç Ã O D A P Ó S - G R A D U A Ç $\tilde{A} O \quad$ N O B R A S I L

ANEXO

Critérios de ExCelêNCIA - Grande Área de Ciências Humanas

(Documento preliminar elaborado pela Grande Área de Ciências Humanas)

O perfil de excelência dos programas de pós-graduação da Grande Área de Ciências Humanas se apóia no tripé constituído por formação, corpo docente e pesquisa e produção cientifica com inserção internacional. A diferenciação entre os níveis 6 e 7 será estabelecida com a gradação, ainda por ser definida, dos critérios abaixo relacionados:

FORMAÇÃO

1) Formação de excelência de pós-graduação com qualidade compatível àquela dos melhores programas internacionais de cada área;

2) Bibliografias que expressem o estado atual da arte;

3) Participação do corpo discente em congressos e seminários no exterior;

4) Fluxo expressivo e constante de estágios sanduíche no exterior.

\section{CORPO DOCENTE}

1) Orientadores com expressiva produção intelectual de nível internacional;

2) Fluxo constante de estágios de formação pós-doutoral;

3) Presença regular de professores visitantes estrangeiros;

4) Cursos e colaborações em atividades de ensino em instituiçóes de reconhecido nível de excelência no exterior;

5) Participação do corpo docente em comitês editoriais e como parecerista de periódicos internacionais;

6) Posições de destaque em instituições e associações científicas de prestígio na área.

\section{Pesquisa E ProduÇÃo CienTífICA COM INSERÇÃo INTERNACIONAL}

1) Publicação de resultados de pesquisa original, sob a forma de livros, capítulos de livros e/ou coletâneas;

2) Publicação de artigos em periódicos internacionais de reconhecida importância;

3) Intercâmbios de pesquisa e convênios ativos firmados com instituiçôes estrangeiras de reconhecido prestígio científico, em regime de reciprocidade e com divulgação no exterior;

4) Programas institucionais de cooperação internacional exigindo missões bilaterais de trabalho;

5) Participação qualificada (conferências, mesas redondas, organização de grupos de trabalho) em eventos científicos internacionais de grande relevância para a área;

6) Promoção de eventos científicos internacionais;

7) Prêmios internacionais;

8) Consultorias a organismos internacionais.

Nota: Índices de impacto e/ou de citação não são critérios importantes para a avaliação de excelência na Grande Área de Ciências Humanas. 
A B S T R A C T University graduate programs are evaluated each year in Brazil by the Ministry of Education through its agency Capes. The evaluation process is a necessary and constantly improved activity. Its most important characteristic is that it is coordinated by the academic community itself, through the work of several evaluation commissions and representatives, each one pertaining to a specific academic discipline or group of disciplines. Special attention is given to the evaluation of the scientific production of the graduate programs. A major drawback of the system is that it fails to closely associate evaluation results with Capes' financial and academic support policies, thus creating "noise" problems which must be quickly eliminated. This text aims at explaining the structure of this evaluation process and how it works.

K E Y W O R D S Capes; graduate programs; evaluation. 